\title{
Density Functional Theory Calculations on Nitrated Boroxines as Possible High Energy-Density Materials
}

\author{
LISA M. INA and DAVID W. BALL', Department of Chemistry, Cleveland State University, Cleveland, OH, USA.
}

ABSTRACT. Density functional theory calculations were performed on a series of nitroboroxine molecules (cyclo-[BO $]_{3}-$ $\left.\left[\mathrm{NO}_{2}\right]_{x} \mathrm{H}_{3-x^{\prime}} \mathrm{x}=1-3\right)$ to determine their thermodynamic properties and assess them as potential high energy materials. Minimum-energy geometries of four boroxine molecules were determined, along with their normal modes of vibration. Analysis of the energies of the molecules and their possible decomposition and combustion products suggests an energy content comparable to that of TNT.

\section{INTRODUCTION}

The search for new high energy-density materials (HEDMs) that would serve as explosives or propellants is an ongoing one. Good HEDMs share certain characteristics: they have a high density, they react (decompose or oxidize) quickly, they produce large amounts of gaseous products, and are thermodynamically unstable with respect to the reaction products (Akhavan 2004). It is for this last requirement that modern computational chemistry software can be applied.

Boroxines are a class of boron-oxygen compounds based on a six-membered ring:

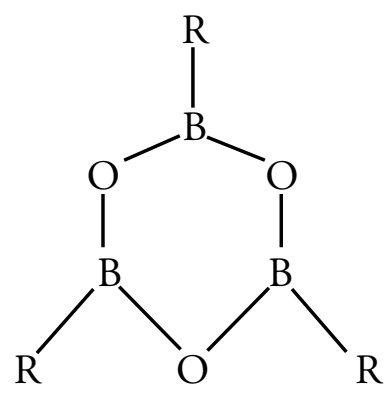

1

Here, the $\mathrm{R}$ group can be $\mathrm{H}$, an inorganic functional group like $\mathrm{NH}_{2}, \mathrm{OH}$, or a halogen, or an organic side chain. They are typically generated by the dehydration/ trimerization of the respective boronic acid, $\mathrm{R}-\mathrm{B}(\mathrm{OH})_{2}$ (Bhat et al. 2011); so-called hetero-boroxines can be synthesized if the precursor boronic acids have different R groups (Tokunaga 2007). Boroxines have

\footnotetext{
${ }^{1}$ Address correspondence to David W. Ball, Department of Chemistry, 2121 Euclid Ave., SR397B, Cleveland, OH 44115. Email: D.BALL@csuohio.edu
}

applications in flame-retardants, batteries, nonlinear optics, catalysis, as precursors to some covalent organic framework compounds, and other uses. Although the six-membered central ring is isoelectronic with benzene, it is currently understood that boroxines do not have aromatic character (Korich and Iovine 2010).

Recently, we have been interested in certain boron compounds as possible HEDMs (Richard and Ball 2006; Richard and Ball 2007; Janning and Ball 2010) because of the thermodynamic stability of the putative product, $\mathrm{B}_{2} \mathrm{O}_{3}$. However, in part because of the stability of $\mathrm{B}_{2} \mathrm{O}_{3}$, many boron compounds are air-sensitive (Greenwood and Earnshaw 1984). By contrast, boroxines are air-stable, suggesting that any HEDM based on the boroxine structure is also likely to be stable in air.

Many HEDMs contain the nitro $\left(\mathrm{NO}_{2}\right)$ group (Akhavan 2004), which not only provides oxygen to oxidize other elements in a molecule, but also contains nitrogen atoms, which can react upon decomposition/ combustion to form very stable $\mathrm{N}_{2}$ gas. Nitrocontaining boroxines appear to be one derivative that has not been explored to date. As such, here we present a computational study of the structure, vibrational frequencies, and thermodynamics of boroxine with one, two, and three nitro groups.

\section{METHODS}

All calculations were performed using the Gaussian suite of programs (Frisch et al. 2009) on a desktop personal computer. The calculations were the DFT method using Becke's 3-parameter exchange functional plus the correlation functional of Lee, Yang, and Parr (abbreviated B3LYP) (Becke 1993, Lee et al. 1988) along with the standard Gaussian basis set labeled 6-311+G(2d,2p). (McLean and Chandler 1980) 
The minimum-energy geometry was confirmed by calculating the vibrational frequencies of the molecule, which all had positive values. Visualization of the molecular orbitals was performed using GaussView (Dennington et al. 2007).

The enthalpies of formation were determined using the reverse gas-phase atomization reactions:

$$
\begin{gathered}
3 \mathrm{~B}+(3+2 x) \mathrm{O}+x \mathrm{~N}+(3-x) \mathrm{H} \rightarrow \\
\text { cyclo- }[\mathrm{BO}]_{3}-\left[\mathrm{NO}_{2}\right]_{x} \mathrm{H}_{3-x}, x=1-3
\end{gathered}
$$

After the energy difference (electronic and thermal) for equation 1 was determined, the energy was corrected for the enthalpy of formation of the proper number of moles of each atom, which was taken from the NIST Chemistry Webbook (NIST, 2016):

$$
\begin{array}{cc}
\mathrm{B}(\mathrm{s}) \rightarrow \mathrm{B}(\mathrm{g}) & \Delta H_{\mathrm{f}}=+565 \mathrm{~kJ} \\
1 / 2 \mathrm{O}_{2}(\mathrm{~g}) \rightarrow \mathrm{O}(\mathrm{g}) & \Delta H_{\mathrm{f}}=+249.18 \mathrm{~kJ} \\
1 / 2 \mathrm{~N}_{2}(\mathrm{~g}) \rightarrow \mathrm{N}(\mathrm{g}) & \Delta H_{\mathrm{f}}=+472.68 \mathrm{~kJ} \\
1 / 2 \mathrm{H}_{2}(\mathrm{~g}) \rightarrow \mathrm{H}(\mathrm{g}) & \Delta H_{\mathrm{f}}=217.998 \mathrm{~kJ}
\end{array}
$$

Once properly corrected for the formation of the atoms, the overall reaction is the enthalpy of formation for the nitroboroxine; from that value, the enthalpies of decomposition and combustion can be determined from standard enthalpies of formation of the products, also taken from the NIST Chemistry Webbook. Because the oxygen balance (OB percent; vide infra) for nitroboroxine is less than zero percent, there are two possible decomposition reactions depending on how the oxygen rearranges. If water is a preferred product, the decomposition reaction is

$$
\mathrm{B}_{3} \mathrm{O}_{3} \mathrm{H}_{2} \mathrm{NO}_{2} \rightarrow \mathrm{H}_{2} \mathrm{O}+1 / 2 \mathrm{~N}_{2}+\mathrm{B}_{2} \mathrm{O}_{3}+\mathrm{B}+1 / 2 \mathrm{O}_{2}
$$

If diboron trioxide is a preferred product, the decomposition reaction is

$$
\mathrm{B}_{3} \mathrm{O}_{3} \mathrm{H}_{2} \mathrm{NO}_{2} \rightarrow 1 / 2 \mathrm{H}_{2} \mathrm{O}+1 / 2 \mathrm{~N}_{2}+3 / 2 \mathrm{~B}_{2} \mathrm{O}_{3}+1 / 2 \mathrm{O}_{2}
$$

Both di- and trinitroboroxine have positive oxygen balances, meaning that the substances have enough oxygen to fully oxidize the other elements (where appropriate). Their decomposition reactions are

$$
\begin{gathered}
\mathrm{B}_{3} \mathrm{O}_{3} \mathrm{H}\left(\mathrm{NO}_{2}\right)_{2} \rightarrow \frac{1 / 2 \mathrm{H}_{2} \mathrm{O}+\mathrm{N}_{2}+3 / 2 \mathrm{~B}_{2} \mathrm{O}_{3}+2 \mathrm{O}_{2}}{[3]} \\
\mathrm{B}_{3} \mathrm{O}_{3}\left(\mathrm{NO}_{2}\right)_{3} \rightarrow 3 / 2 \mathrm{~N}_{2}+3 / 2 \mathrm{~B}_{2} \mathrm{O}_{3}+9 / 2 \mathrm{O}_{2}
\end{gathered}
$$

It is worth noting that nitroboroxines can be considered "green" HEDMs because they give off no carbon dioxide upon decomposition or combustion.

Bond energies were estimated by taking the minimum-geometry structure and erasing all of the molecule except the fragment on each side of the bond, then calculating a single-point energy of the fragment. The bond energy is estimated as the difference in the energies of the two fragments and the entire molecule.

Densities of the molecules were estimated using the VOLUME keyword in Gaussian and combining that value with the molar mass. The VOLUME keyword uses a Monte Carlo integration to determine the volume within a density contour of 0.001 electrons/ Bohr $^{3}$. Because an integration of this type has some degree of randomness to it, the volume calculation was performed 100 times for each molecule, and the average volume was used. The VOLUME=TIGHT option was used for better accuracy; it causes the program to evaluate the density contour at five times more points than otherwise.

\section{RESULTS}

Figure 1 shows the minimum-energy structures of nitroboroxine, dinitroboroxine, and trinitroboroxine, while Table 1 lists some structural parameters of the three molecules. The central six-membered ring is flat and roughly hexagonal, although the distortion from perfectly hexagonal is rather obvious from the $\mathrm{B}-\mathrm{O}$ bond distances and the O-B-O bond angles in Table 1 . Nitroboroxine has three different B-O bond distances, depending on the distance from the $\mathrm{BNO}_{2}$ part of the molecule. Similarly, in dinitroboroxine the B-O distance depends on the bond's position with respect to the $\mathrm{B}-\mathrm{H}$ group. The larger $\mathrm{O}-\mathrm{B}-\mathrm{O}$ bond angles in nitro- and dinitroboroxine are found for the boron atoms that have the $\mathrm{NO}_{2}$ groups attached to them. The $\mathrm{NO}_{2}$ bond angles stay roughly constant, and in all cases the $\mathrm{NO}_{2}$ group(s) is/are essentially perpendicular to the central boroxine six-membered ring. 


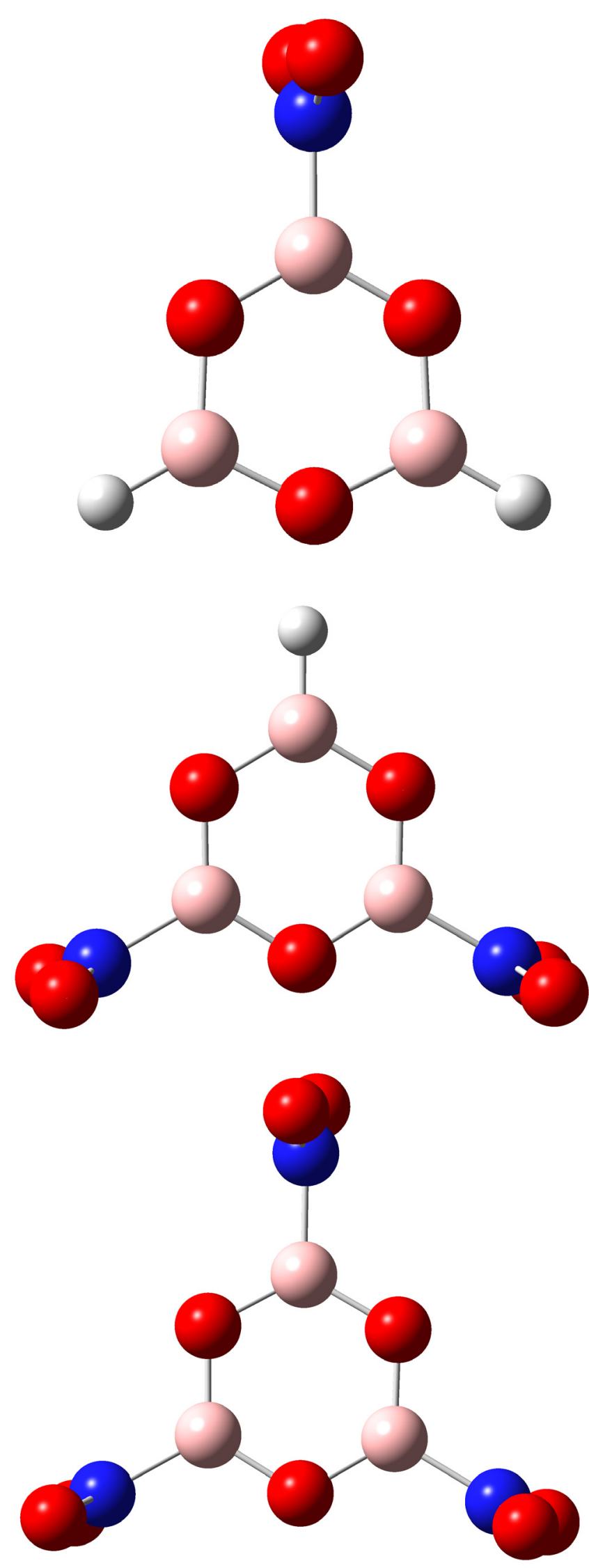

FIGURE 1. Minimum-energy structures of nitroboroxine (top), dinitroboroxine (middle) and trinitroboroxine (bottom). The molecules are twisted slightly to show the far oxygen atoms on the $\mathrm{NO}_{2}$ groups.
Although nogeometry constraints were imposed on the molecules as part of the geometry optimization, it is clear from the structures that both nitroboroxine and dinitroboroxine have nominal $\mathrm{C}_{2 \mathrm{v}}$ symmetry, while trinitroboroxine belongs to the $\mathrm{D}_{3 \mathrm{~h}}$ point group.

Figure 2 shows the vibrational absorption spectra for the three molecules, set to the same horizontal scale. According to a group theoretical analysis, the symmetry species of the vibrations transform as follows:

$$
\begin{aligned}
& \text { nitroboroxine: } \Gamma_{\text {vib }}=10 \mathrm{~A}_{1} \oplus 3 \mathrm{~A}_{2} \oplus 8 \mathrm{~B}_{1} \oplus 6 \mathrm{~B}_{2} \\
& \text { (in } \mathrm{C}_{2 \mathrm{v}} \text { ) } \\
& \text { dinitroboroxine: } \Gamma_{\text {vib }}=11 \mathrm{~A}_{1} \oplus 5 \mathrm{~A}_{2} \oplus 10 \mathrm{~B}_{1} \oplus 7 \mathrm{~B}_{2} \\
& \text { (in } C_{2 v} \text { ) } \\
& \text { trinitroboroxine: } \Gamma_{\text {vib }}=5 \mathrm{~A}_{1}^{\prime} \oplus 3 \mathrm{~A}_{2}^{\prime} \oplus 8 \mathrm{E}^{\prime} \oplus \\
& \begin{array}{l}
1 \mathrm{~A}_{1}^{\prime \prime \oplus} 4 \mathrm{~A}_{2}^{\prime \prime} \oplus \mathrm{E}^{\prime \prime} \\
\quad\left(\text { in } D_{3 h}\right)
\end{array}
\end{aligned}
$$

In $C_{2 v}$, the $\mathrm{A}_{1}, \mathrm{~B}_{1}$, and $\mathrm{B}_{2}$ modes are infrared-active, while in $D_{3 b}$ only the $\mathrm{E}^{\prime}$ and $\mathrm{E}^{\prime \prime}$ modes are active. As such, we would expect to see as many as 24 singlydegenerate, 28 singly-degenerate, and 13 doublydegenerate vibrations in the absorption spectra of nitroboroxine, dinitroboroxine, and trinitroboroxine, respectively. A close inspection of Figure 2 shows that vibrations with non-zero intensities, as indicated by the blue vertical lines in the spectra, do indeed count up to these numbers.

Table 2 lists the various enthalpies of reaction as determined by this study. The calculated values of the electronic energy, $E_{\text {electronic }}$, and thermal energy, $E_{\text {thermal' }}$, are given as reference values. The oxygen balance (OB percent) is given by the following formula (Persson et al. 1993):

$$
\mathrm{OB} \%=-\frac{32003 / 4 b+1 / 4 h+0 n-1 / 2 o)}{\mathrm{MW}}
$$

where $b$ is the number of boron atoms in the molecule, $b$ is the number of hydrogen atoms in the molecule, $n$ is the number of nitrogen atoms, and $o$ is the number of oxygen atoms. The denominator term MW is the molar mass of the molecule. The OB percent is an indication of whether or not a compound has enough oxygen to completely oxidize the other elements (except nitrogen) and in some cases is suggestive of what products are 
TABLE 1

Structural parameters of nitro-, dinitro-, and trinitroboroxine.

Distances in angstroms, angles in degrees. Cf. Figure 1.

\begin{tabular}{lccc}
\hline \hline Parameter & Nitroboroxine & Dinitroboroxine & Trinitroboroxine \\
\hline$r(\mathrm{~B}-\mathrm{O})$ & $1.355,1.374,1.388$ & $1.354,1.366,1.385$ & 1.364 \\
$r(\mathrm{~B}-\mathrm{H})$ & 1.180 & 1.177 &.-- \\
$r(\mathrm{~B}-\mathrm{N})$ & 1.532 & 1.525 & 1.520 \\
$r(\mathrm{~N}-\mathrm{O})$ & 1.227 & 1.226 & 1.225 \\
$\alpha(\mathrm{O}-\mathrm{B}-\mathrm{O})$ & $118.5,122.2$ & $117.9,120.0$ & 121.9 \\
$\alpha(\mathrm{O}-\mathrm{B}-\mathrm{H})$ & 120.1 & 121.1 & -- \\
$\alpha(\mathrm{O}-\mathrm{B}-\mathrm{N})$ & 118.2 & 119.1 & 119.1 \\
$\alpha(\mathrm{O}-\mathrm{N}-\mathrm{O})$ & 125.8 & 126.3 & 126.7 \\
\hline
\end{tabular}

TABLE 2

Energy results for the optimized structures of nitroboroxine, dinitroboroxine, and trinitroboroxine.

\begin{tabular}{|c|c|c|c|}
\hline & Nitroboroxine & Dinitroboroxine & Trinitroboroxine \\
\hline Eelectronic, $\mathrm{h}$ & -506.97295 & -711.56544 & -916.13933 \\
\hline$E_{\text {thermal, }} \mathrm{kJ} / \mathrm{mol}$ & 172.98 & 189.1 & 204.7 \\
\hline $\mathrm{OB} \%$ & -6.2 & 18.5 & 33.0 \\
\hline Density, $\mathrm{g} / \mathrm{cm}^{3}$ & 1.61 & 1.76 & 1.87 \\
\hline 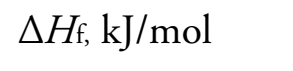 & -1144.4 & -1214.9 & -1237.2 \\
\hline$\Delta H_{\mathrm{dec}}, \mathrm{kJ} / \mathrm{mol}^{*}$ & $-414.9,-908.8$ & -838.3 & -637.1 \\
\hline$\Delta H_{\mathrm{dec}}, \mathrm{kJ} / \mathrm{g}^{*}$ & $-3.23,-7.08$ & -4.83 & -3.24 \\
\hline$E(\mathrm{~B}-\mathrm{N}), \mathrm{kJ} / \mathrm{mol}$ & 311 & 336 & 326 \\
\hline
\end{tabular}


preferred (Akhavan 2004). The calculated densities are listed inF Table 2, and show that the predicted density increases as the number of nitro groups increase. Two values for the enthalpy of decomposition, $\Delta H_{\mathrm{dec}}$, are given for nitroboroxine because of the two possible decomposition reactions. Because the energy given off per unit mass is an important indicator of the efficacy of the HEDM, we also report values of $\Delta H_{\text {dec }}$ in units of $\mathrm{kJ}$ per gram.

Finally, because previous research suggests that the bond to the nitro group is usually the weakest (and therefore among the first to break upon decomposition)
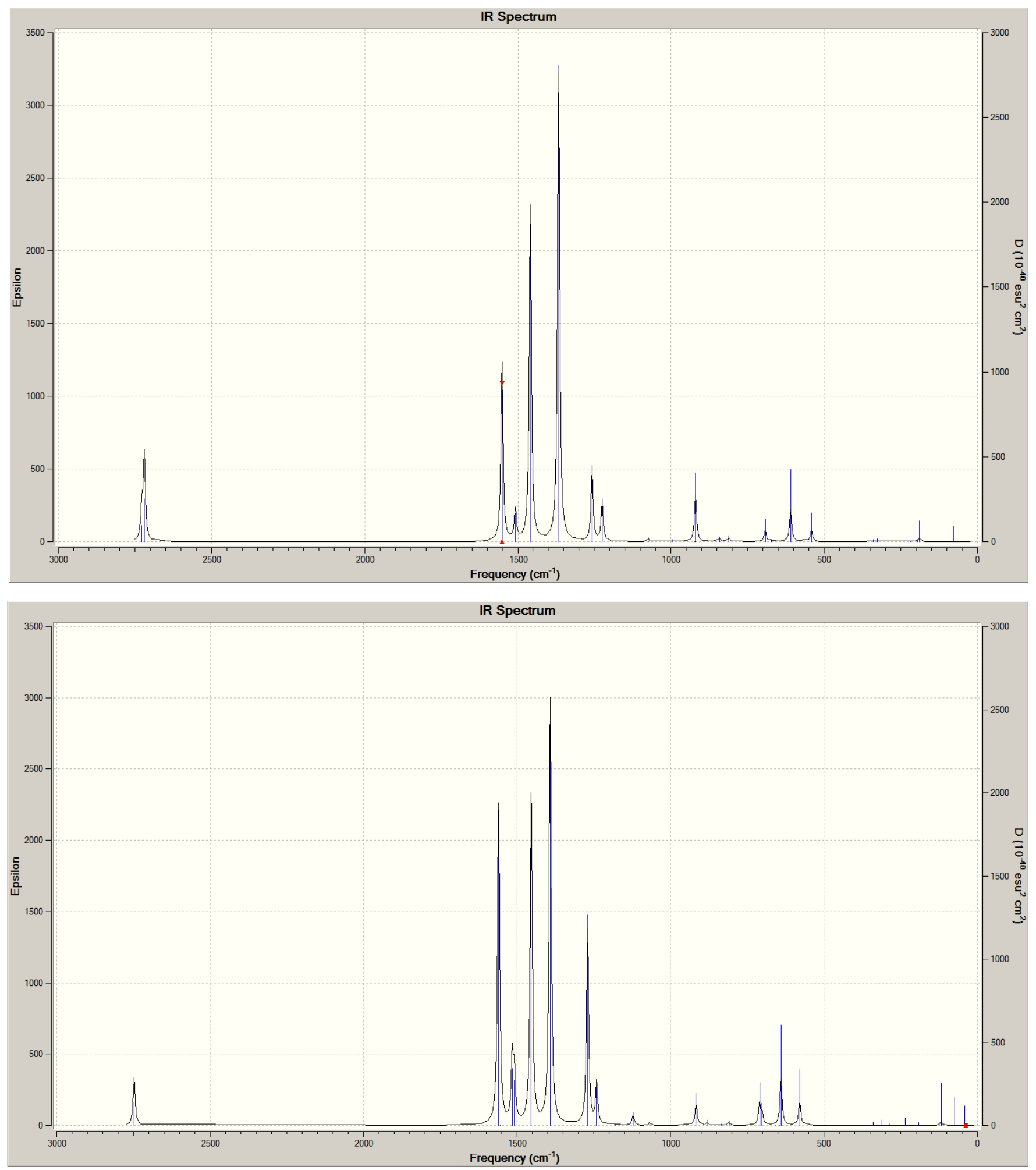

FIGURE 2. Predicted infrared absorption spectra for nitroboroxine (top), dinitroboroxine (bottom), and trinitroboroxine (next page). The bottom spectrum truncates around $1800 \mathrm{~cm}^{-1}$ because there are no additional absorptions at higher wavenumbers. 
(Murray etal. 2009), Table 2 lists the calculated B-NO $\mathrm{NO}_{2}$ bond energies.

\section{DISCUSSION}

The structures of the three boroxine derivatives show no surprises. The boron-oxygen bond distances, which vary from $1.354 \AA$ to $1.388 \AA$ and define the central six-membered ring are all very close to the $1.366 \AA$ average value for a tri-coordinate boron atom (Greenwood and Earnshaw 1984), which span the range $1.28-1.43 \AA$. The fact that all of the $\mathrm{NO}_{2}$ groups optimized as being perpendicular to the sixmembered ring is also not surprising, as a structure with the nitro groups coplanar with the ring would put the electronegative oxygen atoms of the $\mathrm{NO}_{2}$ groups in proximity with the electronegative oxygen atoms of the ring. The perpendicular orientation minimizes electrostatic repulsion.

The vibrational spectra also showed no significant deviations from expectations. The spectra of nitroboroxine and dinitroboroxine are so similar that it may be difficult to differentiate the two compounds on the basis of the infrared absorption spectrum alone. The lone B-H stretching mode is slightly higher in wavenumber, at $2751 \mathrm{~cm}^{-1}$, for nitroboroxine than the two near-degenerate asymmetric and symmetric B-H stretching modes for dinitroboroxine (2723 and
$2732 \mathrm{~cm}^{-1}$, respectively). However, these values are for gas-phase molecules; in the condensed phase these absorptions would be shifted and broadened, lessening their ability to distinguish between substances. The fairly strong absorptions between 1220 and 1450 $\mathrm{cm}^{-1}$ are various modes of the boron-oxygen sixmembered ring, which all three molecules share. The strong absorptions between 1510 and $1575 \mathrm{~cm}^{-1}$ are asymmetric and symmetric stretching vibrations of the nitro $\operatorname{group}(s)$, and while dinitroboroxine has four normal modes in this range while nitroboroxine has only two, the modes are near-degenerate and only two individual absorptions appear in the absorption spectrum, even for the gas-phase molecules. Although trinitroboroxine would be distinguished by its lack of a B-H stretching absorption around $2730-50 \mathrm{~cm}^{-1}$ and any B-H wag around $915 \mathrm{~cm}^{-1}$ (see Figure 2), the very strong absorptions in the $1200-1600 \mathrm{~cm}^{-1}$ region appear at almost the same place as nitro- and dinitroboroxine.

The trend towards increased density with an increasing number of nitro groups is interesting. At $1.61 \mathrm{~g} / \mathrm{cm}^{3}$, nitroboroxine is almost as dense as TNT $\left(1.65 \mathrm{~g} / \mathrm{cm}^{3}\right.$; Akhavan 2004$)$, and the density increases as a second and third nitro group are added. This would generally be considered a positive property, as Kamlet and Jacobs (Kamlet and Jacobs 1968)

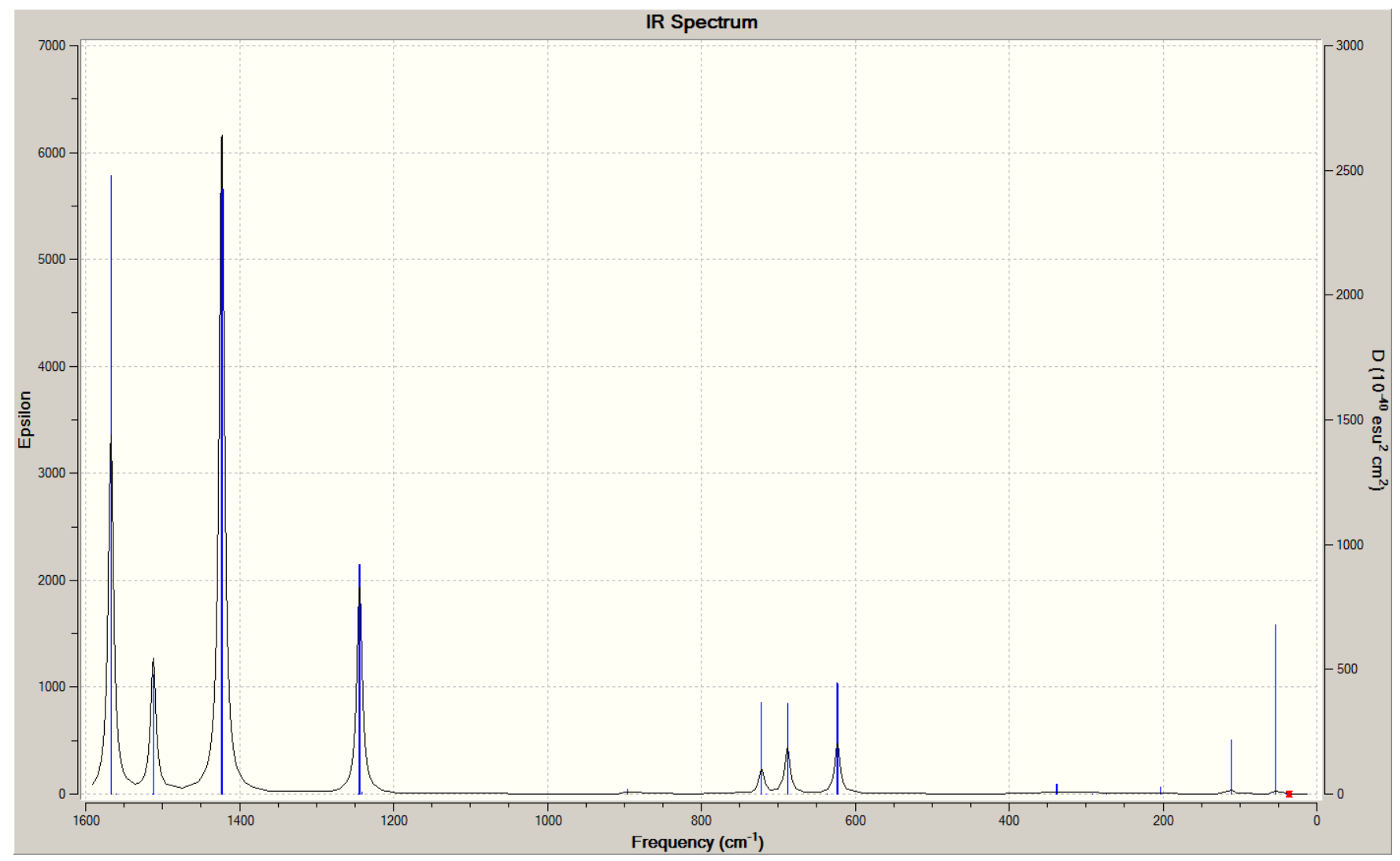


have modeled that certain detonation properties are related to the square of the HEDM density. The predicted density of trinitroboroxine rivals that of HMX (cyclotetramethylene tetranitramine), one of the most common high explosives (Akhavan 2004).

The calculated enthalpies of formation for the three boroxine compounds are all very negative. This is not completely unexpected, as the boron-oxygen bond is a very energetically-stable one. It does raise the question of how much energy would be given off as the compounds decompose. Table 2 shows that depending on the compound and the actual

\section{TABLE 3}

\section{Comparisons of specific enthalpies of decomposition of other HE materials with nitospiropentanes (previous data taken from Akhaven 2004).}

\begin{tabular}{|c|c|}
\hline HE material & $\left|\Delta H_{\text {dec }}\right| \mathrm{kJ} / \mathrm{g}$ \\
\hline nitroglycerine & 6.19 \\
\hline ethylene glycol dinitrate & 6.66 \\
\hline pentaerythritol tetranitrate & 5.79 \\
\hline cyclotrimethylenetrinitramine & 5.04 \\
\hline cyclotetramethylenetetranitramine & 5.01 \\
\hline nitroguanidine & 2.47 \\
\hline picric acid & 3.25 \\
\hline tetryl & 4.34 \\
\hline triaminotrinitrobenzene & 3.50 \\
\hline hexanitrostilbene & 3.94 \\
\hline trinitrotoluene & 4.25 \\
\hline \multicolumn{2}{|l|}{$* * * * * * * * * * * * * * * * * * * * * * * * * * * \pi$} \\
\hline nitroboroxine & $3.23,7.08$ \\
\hline dinitroboroxine & 4.83 \\
\hline trinitroboroxine & 3.24 \\
\hline
\end{tabular}

products formed, the amount of energy per unit mass may rival current HEDMs. (A specific enthalpy, in terms of energy given off per unit mass, is a better comparison between HEDMs than a molar enthalpy.) For nitroboroxine, if $\mathrm{B}_{2} \mathrm{O}_{3}$ were the preferred product, the specific enthalpy of decomposition is just over seven $\mathrm{kJ}$ per gram, which actually outperformed some currently-used HEDMs, as shown in Table 3. However, if $\mathrm{H}_{2} \mathrm{O}$ were the preferred decomposition product, the specific enthalpy of decomposition drops to just less than that of picric acid, the lowest-energy HEDM in the table. It is likely that kinetic factors will impact the exact specific enthalpy of decomposition. For dinitroboroxine, the specific enthalpy of decomposition rivals that of many of the table entries, and it even slightly higher than that of trinitrotoluene (TNT), which is a standard against which other HEDMs are measured. However, in going to trinitroboroxine, the specific enthalpy of decomposition decreases, once again rivaling the lowest value in Table 3 . The likely reason can be seen in Equation 4: Although 3/2 mol of energetically-stable $\mathrm{B}_{2} \mathrm{O}_{3}$ are formed (as is found in all three boroxines), no energetically-stable water is formed. It should be pointed out, however, that a total of six moles of gaseous products are formed per mole of trinitroboroxine, so what this compound may lack in specific enthalpy it may make up for in detonation pressure.

As Murray et al. found (Murray et al. 2009), weakerthan-expected C-NO $\mathrm{N}_{2}$ or $\mathrm{N}-\mathrm{NO}_{2}$ bonds are likely the "trigger linkages" for the decomposition process. An estimate of the bond energy to the nitro group can be a useful meter stick for comparisons. Table 3 also lists the calculated $\mathrm{B}-\mathrm{NO}_{2}$ bond energies for the three boroxine compounds. Because the structures of the $\mathrm{NO}_{2}$ groups themselves are slightly different depending on the molecule, the estimated bond energies vary somewhat but are generally about $325 \pm 10 \mathrm{~kJ} / \mathrm{mol}$. These values are higher than the energies of the C-NO and $\mathrm{N}-\mathrm{NO}_{2}$ bonds determined by Murray et al.; the $\mathrm{C}-\mathrm{NO}_{2}$ bond energies ranged from 157 to $318 \mathrm{~kJ} /$ mol, while the $\mathrm{N}-\mathrm{NO}_{2}$ bond energies ranged from 158 to $192 \mathrm{~kJ} / \mathrm{mol}$. The $\mathrm{B}-\mathrm{NO}_{2}$ bonds may be stronger because of a presumed dative interaction between the lone electron pair on the $\mathrm{N}$ atom and the empty $p$ orbital on the $\mathrm{B}$ atom, an interaction whose energy has been estimated to be about $74 \mathrm{~kJ} / \mathrm{mol}$ (Leroy et al. 1993). Without this additional bond energy, the $\mathrm{B}-\mathrm{NO}_{2}$ bonds would have a strength commensurate with X-NO 2 bonds in other known HEDM materials. 
Whether or not this disqualifies the nitroboroxines as true HEDMs must be determined by experiment, as kinetic and sensitivity factors are also aspects of good high energy-density materials.

\section{ACKNOWLEDGEMENTS}

Thanks to the Department of Chemistry, Cleveland State University, for support.

\section{LITERATURE CITED}

Akhavan J. 2004. The Chemistry of Explosives. Cambridge: Royal Society of Chemistry. $180 \mathrm{p}$.

Becke AD. 1993. Density-functional thermochemistry. III. The role of exact exchange. J. Chem. Phys. 98:5648-5652. https:// doi.org/10.1063/1.464913

Bhat KL, Markham GD, Larkin JD, Bock CW. 2011. Thermodynamics of boroxine formation from the aliphatic boronic monomers $\mathrm{R}-\mathrm{B}(\mathrm{OH})_{2}\left(\mathrm{R}=\mathrm{H}, \mathrm{H}_{3} \mathrm{C}, \mathrm{H}_{2} \mathrm{~N}, \mathrm{HO}\right.$, and F): a computational investigation. J. Phys. Chem. A. 115(26):7785-7793. https://doi.org/10.1021/jp202409m

Dennington RD 2nd, Keith TTM, Millam JM. GAUSSVIEW [computer program]. Version 5.0. Shawnee Mission (KS): Semichem, Inc.; 2007..

Frisch MJ, Trucks GW, Schlegel HB, Scuseria GE, Robb MA, Cheeseman JR, Scalmani G, Barone V, Mennucci B, Petersson GA, et al. GAUSSIAN 09 [computer program]. Wallingford (CT): Gaussian, Inc.; 2009.

Greenwood NN, Earnshaw A. 1984. Chemistry of the Elements. Oxford: Pergamon Press. 1542 p.

Janning JD, Ball DW. 2010. Nitroborazines as potential high energy materials: density functional theoretical calculations. J. Mol. Model. 16(5):857-62. https://doi.org/10.1007/ s00894-009-0586-y

Kamlet MJ, Jacobs SJ. 1968. Chemistry of detonations. I. A simple method for calculating properties of $\mathrm{CNHO}$ explosives. J. Chem. Phys. 48:23-35. https://doi.org/10.1063/1.1667908
Korich AL, Iovine PM. 2010. Boroxine chemistry and applications: a perspective. Dalton Trans. 39:1423-1431. https://doi.org/10.1039/B917043J

Lee C, Yang W, Parr RG. 1988. Development of the Colle-Salvetti correlation-energy formula into a functional of the electron density. Phys. Rev. B. 37:785-789. https://doi.org/10.1103/ PhysRevB.37.785

Leroy G, Sana M, Wilante C. 1993. Evaluation of the bond energy terms for the various types of boron-nitrogen bonds. Theo. Chim. Acta. 85(1):155-166. https://doi.org/10.1007/ BF01374585

McLean AD, Chandler GS. 1980. Contracted Gaussianbasis sets for molecular calculations. 1. 2nd row atoms, $\mathrm{Z}=11$-18. J. Chem. Phys. 72:5639-5648. https://doi. org $/ 10.1063 / 1.438980$

Murray JS, Concha MC, Politzer P. 2009. Links between surface electrostatic potentials of energetic molecules, impact sensitivities and $\mathrm{C}-\mathrm{NO}_{2} / \mathrm{N}-\mathrm{NO}_{2}$ bond dissociation energies. Mol. Phys. 107:89-97. https://doi. org/10.1080/00268970902744375

NIST. 2016. Chemistry Webbook. https://webbook.nist.gov/ chemistry. Accessed 23 May 2016.

Persson PA, Holmberg R, Lee J. 1993. Rock Blasting and Explosives Engineering. Boca Raton (FL): CRC Press. $560 \mathrm{p}$.

Richard RM, Ball DW. 2006. G2, G3, and complete basis set calculations of the thermodynamic properties of boroncontaining rings: cyclo- $\mathrm{CH}_{2} \mathrm{BHNH}, 1,2-$, and 1,3- cyclo$\mathrm{C}_{2} \mathrm{H}_{4} \mathrm{BHNH}$. J. Mol. Struct.-THEOCHEM. 776(1-3):8996. https://doi.org/10.1016/j.theochem.2006.08.036

Richard RM, Ball DW. 2007. Optimized geometries, vibrational frequencies, and thermochemical properties of mixed boronand nitrogen-containing three-membered rings. J. Mol. Struct.-THEOCHEM. 806(1-3):113-120. https://doi. org/10.1016/j.theochem.2006.11.018

Tokunaga Y, Ueon H, Shimomura Y. 2007. Formation of heteroboroxines: dynamic combinatorial libraries generated through trimerization of pairs of arylboronic acids. Heterocycles. 74(1):219-223. https://doi.org/10.3987/COM-07-S(W)61 